\title{
ENERGY CONSUMPTION OF OLIVE OIL EXTRACTION BY DIFFERENT METHODS
}

\author{
Arafa G. K. ${ }^{1}$ and A. A. Abd El-Rahmam ${ }^{2}$
}

\section{ABSTRACT}

A study was conducted on the evaluation of energy use in traditional and machinery methods to extract oil in olive oil Company in Agricultural Research Center revealed. The objectives of the study were: (1) To determine and identify the level of consumption of the energy sources in use., (2) To determine energy consumption for oil production in two extraction olive oil methods., and (3) To enhance oil production with minimum energy input though olive oil industry to relate energy use. The obtained results were as follow: a) Physical and mechanical properties of olive fruits. It noticed that the values were from 2.02 to $2.55 \mathrm{~cm}$, from 1.58 to $1.944 \mathrm{~cm}$, from 2.88 to $5.23 \mathrm{~g}$, from 50 to $49.85 \%$, and from 530 to $502 \mathrm{~N}$ for length, width, weight, moisture content, and hardness., $b$ ) The major energy sources were manual, MRT and electrical energies. MRT energy was the highest energy consumed. MRT energy consumptions, mostly expended in operating of manufacture, transport, and repairs were 2114.7 and 47329 MJ for traditional and machinery methods., and c) Traditional and electrical energy were expended in operating machines was found to be the least consumed energy with values were (13.5 and $6.75 \mathrm{MJ}$ ) and (132.8 and $209.2 \mathrm{MJ}$ ) for traditional and machinery methods, respectively

Key words: Olive fruits, Extraction, Traditional, Mechanical, Energy, Oil and Consumption.

\section{INTRODUCTION}

7 he average olive oil content ranged between 18.3 and $25.4 \%$ on fresh matter basis in olive fruit. Olive oil considering of edible 1 liquid oils directly without any chemical treatments where it is the fruit of the olive juice natural. An energy input is required in food processing, as well as in packaging, distribution and storage. Many food crops when harvested cannot be consumed directly, but must pass through several stages of processing in order to be palatable and digestible.

1- Senior Researcher, Agric. Eng. Res. Institute, Agric. Res. Center, Egypt.

2- Head of Researchers, Agric. Eng. Res. Institute, Agric. Res. Center, Egypt. 
The cultivated area of olive trees in 2014 about 227683 fed. (fruitful area of 165903 fed. the quantity of oil, about 4 thousand tons are extracted from about 35 to 40 thousand tons of fruits. Technical bulletin No. 2/2014 by the Ministry of Agriculture and Land Reclamation of Egypt. Pimentel (1992) reported that the energy is one of the most valuable inputs in agricultural production. It is invested in various forms such as mechanical (from machines, human labour, and animal draft), chemical (fertiliser, pesticides, herbicides), electrical, heat, etc. The amount of energy used in agricultural production, processing and distribution should be significantly high in order to feed the expanding population and to meet other social and economic goals. Jekayinfa and Olafimihan (2000) mentioned that the energy analyses of food processing systems, who developed an energy model to assess the requirements of electricity, fuel and labour for rice handling storage and milling in a rice-processing complex in Korea. Abubakar and Umar (2006) indicate that the agroprocessing industry transforms products originating from agriculture into both food and non-food commodities. Processes range from simple preservation (such as sun-drying) and operations closely related to harvesting, to the production, by modern, capital-intensive methods of textiles, pulp, paper, etc. Upstream industries are engaged in the initial processing of products such as rice and flour milling, leather tanning, cotton ginning, oil pressing, saw milling and fish canning. Chinnan et al. (1980) mentioned that olives must be processed within 24 hours. However this not always possible. You should aim to have fruit processed within a maximum of three days from harvest. If this does not look feasible, olives must be kept in a cool, dark, well aerated place. Greener olives will store longer than more mature black olives. Fully ripe (black) olives must be processed within 48 hours to obtain high quality olive oil.

Herz (1997) mentioned that an oil can be extracted mechanically with a ram press, an expeller or even a wooden mortar and pestle, a traditional method that originated in India. Presses range from small, hand-driven models that an individual can build to power-driven commercial presses. The ram press uses a piston inside a cage to crush the seed and force out the oil. Gutierrez et al. (1999) reported that in the Mediterranean 
region, healthy, interesting nutritional and sensorial properties of olive oil have been known for a long time. Olive oil being the main fat source of the diet due to its use without refining, which attributes its distinguishable characteristics such as: aroma, taste, color and nutritive properties than other vegetable oils. Owen et al. (2000) mentioned that the olive oil is a fine product with high nutritional value and significant health benefits quality olive oils are expensive owing to the hard and time- consuming tasks involved in the cultivation of olive trees, the harvesting of the fruits, and the extraction of the oil. For this reason, adulteration of higher quality olive oils with either seed oils or olive oils of lower quality is a relatively common fraudulent practice. Akinbami et Al. (2001) explained that the realizing the oil from the plant tissues begins by crushing the olives. The object is to tear the flesh cells to let the oil run out the vacuoles, thus permitting the formation of larger drops that can then be separated from other phases. There are two principal types of mill used today ; (1) Stone mills (roller mills), and (2) Metal crushers. Boskou et al. (2005) mentioned that the continuous interest in the phenolic compounds of virgin olive oil (VOO) has also been extended to all products of the olive tree that can be consumed as common foods (table olives, olive paste) or used as sources for them (raw olives, olive leaves). Van Gerpen (2006) mentioned that the refining of oil usually consists of two steps. The first step is degumming and the second step is neutralization, in which the free fatty acids (FFAs) in the crude oil are caustic-stripped with sodium hydroxide $(\mathrm{NaOH})$ in an aqueous solution. The resulting soap stock is settled, filtered or centrifuged out. Alam (2007) mentioned that a rule of thumb is that the moisture content of the seed should be close to 10 percent. The number varies considerably for specific oilseeds. For example, rapeseed should be dried to a 7-percent moisture content, camelina to about 6 percent and sunflower to 8.5 percent. Safflower needs only to be dried to 11 percent and soybean is safe for storage and processing at 12 percent. Kurki et al. (2008) said that the preparation of the raw material often includes removing husks or seed coats from the seeds and separating the seeds from the chaff. There are a wide variety of small- to intermediate-scale approaches to and technologies for effective seed cleaning. Pilgeram 
(2008) explain that this is a distillation process of oil that occurs at high temperatures and low pressure. The oil is put under a vacuum and heated with steam to remove any leftover taste or odors and FFAs. Deodorizing can also be achieved by treatment with activated charcoal . Fellows, Peter, and Ann Hampton (1992) said that use clean, dry containers to package and store oils. Sealed glass or plastic bottles are adequate for small quantities. Colored containers in a dark box help increase shelf life. Steel or plastic tanks work well for large quantities. The shelf life of oil is usually six to 12 months if it is properly packaged and kept away from heat and sunlight. Van Gerpen (2008) indicated that the keeping air away from oil is perhaps the most important step to prevent rancidity. Completely fill whatever size container you chose so there is no air space and then cap the container tightly. The objectives of the study were: (1) To determine energy consumption for oil production in two extraction olive oil methods., (2) To calculate the energy use ratios of the oil extraction, and (3) To enhance oil production with minimum energy input though olive oil extraction to relate energy use.

\section{MATERIAL AND METHODS}

The present study was conducted on the evaluation of energy use patterns in two olive oil extraction methods (traditional and machinery methods) in Egypt. Energy use and production data in the two methods for season 2013 were done in oil olive extraction company, Agricultural Research Center. Two different processes are used today for olive oil production (Fig. 1), the so-called traditional process, and the machinery process based on a 2-phase decanter. These by-product fractions are mainly composed of solid and liquid phases.

\section{Measurments:}

Moisture content was determined by measuring the mass difference when $10 \mathrm{~g}$ of olive fruits were dried in an oven at $105{ }^{\circ} \mathrm{C}$ for $5 \mathrm{~h}$.

Digital balance, source of manufacture: Germany; Model: SBA 51; and Accuracy $0.01 \mathrm{~g}$. It was used to determine the weight of individual fruit.

Digital vernier caliper, it has an accuracy of $0.01 \mathrm{~mm}$. It was used to measure the dimensions of individual fruit.

Hardness test, hardness of the samples were tested using hardness tester (model 174886 kiya seisakusho LTD). The hardness value of each 
sample was recorded in kilogram and calculated in Newten. Due to continuous improvements of the product. All machinery parts made from stainless steel. Units of machinery with the following technical specifications:

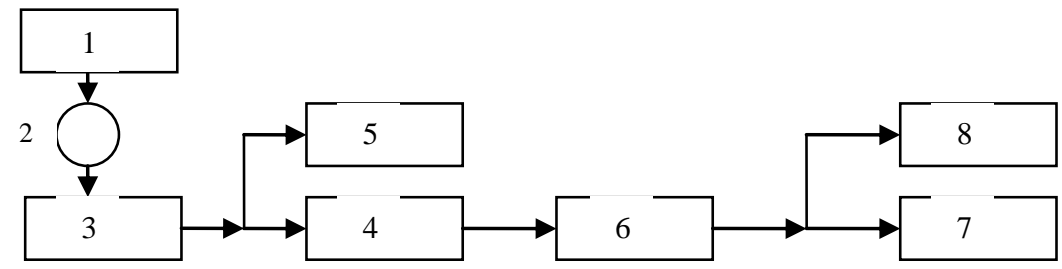

1- Washing machine,2- Milling machine, 3- Pressing, 4- Pomace, 5- Oil and water, 6- Separator, 7- Oil, and 8-Vegetables water

a) Traditional process.

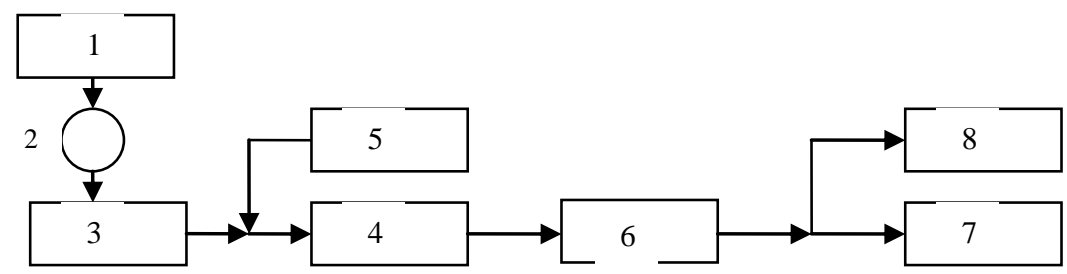

1- Washing machine,2-Crushing machine, 3- Malaxing machine, 4- Decanter to separate pomace , 5-Add water , 6- Separator, 7- Olive oil, and 8-Vegetables water

b) phase decanter process.

Fig. 1: Diagram for steps extraction olive oil by traditional and mechanical methods.

\section{1- Extraction by cold pressing (Traditional methods) :}

Expellers, have a rotating screw inside a horizontal cylinder that is capped at one end. The screw forces the seeds for increasing pressure, with weight of expeller hydraulic $120 \mathrm{~kg}$.

Transporting the olives, olives have been transported fruits into rigid plastic boxes.

Sample preparation, after delivery, the olives are freed from leaves, twigs and other light matter before the washing machine removes sand and soil. 
Washing the olives, the olive washing machines consist of mechanisms which stir the fruit in water and devices for separating one from the other.

Crushing, can handle $300-350 \mathrm{~kg}$ of olives and use $5-8 \mathrm{~kW}$ of power.

Pressing, the method of extracting the oil from olives is to force it out by pressure using hydraulic presses. The pressure is built up slowly to not higher than about 400 bar, to remove the mixture olive oil and vegetable water.

Mixing, after olive has been crushed, the olive paste has to be mixed, for subsequent separation of the solid phase from the liquid phases.

Extraction of oil from macerated pulp (olive paste), the finely ground and maxine paste of olive fruits is processed by hydraulic disc presses.

Clarification, to removes contaminants such as fine pulp, water and resins. You can clarify oil by allowing it to sit undisturbed for a few days and then removing the upper layer. For further clarification, filter the oil through a fine filter cloth.

\section{2- Machinery methods:}

Standard Scale, maximum weight: $65 \mathrm{~kg}$., Accuracy: 1 gram.

Washing bath to olives (Washing),

- Structure is building with wheels to its easy movement.

- The olives are introduced in the hopper, when they are taken in the washing.

\section{Unit to Cushing, Centrifugation and Decanting,}

- Capacity of the feed hopper: $50 \mathrm{Kg}$. - Initial time of crush 30 minutes.

- Initial time of mixed 1 hour. - Quantity of oil in 1 hour 40-50 kg.

- Install powers $3 \mathrm{~kW}$.

- Weight: $380 \mathrm{~kg}$.

Centrifugation: In centrifuge process macerated pulp is diluted by water and pumped into the decanter which separates the solid phase (olive pomace) from the liquid phase (olive oil + vegetable water). Rotating speed of decanter is about 3.000-4.000 r.p.m.

Extraction oil is separated by horizontal decanting centrifuges (decanters) 
- Liquid phase (oil + water) goes to centrifugal separator and olive oil is separated from water phase.

\section{Pulverization unit,}

Efficiency $200 \mathrm{~kg} / \mathrm{h}$ with screen $8 \mathrm{~mm}$., power: $1 \mathrm{HP}$ electrical., weight: $10 \mathrm{~kg}$., and optionally: crush of oleaginous, with approximated efficiency of 20 to $30 \mathrm{~kg} / \mathrm{h}$.

\section{Plates filter:}

Built in stainless steel with structure in wheels., electro-pump in stainless steel and motor is built with special voltage., these plates filter have 10 plates., weight: $28 \mathrm{~kg}$, and production: $600 \mathrm{~b} / \mathrm{h}$.

\section{Bottling unit (Bottling),}

- Estimate production by the tap $120 \mathrm{l} / \mathrm{h}$.

- Type of pump, this pump has a motor with a feed elastic band.

\section{Energy Consumption:}

Table (1): Requirements of energy per unit.

\begin{tabular}{|l|c|c|}
\hline $\begin{array}{l}\text { Requirements of energy per } \\
\text { unit }\end{array}$ & Value & Reference \\
\hline Manpower, MJ/ h. & 0.75 & Norman, 78 \\
\hline Female power, MJ/ h. & 0.68 & Norman, 78 \\
\hline Electricity, MJ/ kWh & 11.99 & Pimentel, 92 \\
\hline MRT, MJ/ kg weight machine & 100.7 & Bridges and smith, 79 \\
\hline Olive oil, MJ/ kg & 0.5 & $\ldots$. \\
\hline
\end{tabular}

Table (2): Requirements of extraction olive oil by traditional and machinery methods.

\begin{tabular}{|l|c|c|}
\hline Requirements of extraction olive oil & Traditional & Machinery \\
\hline Feeding rate, $\mathrm{kg} / \mathrm{h}$. & 300 & 300 \\
\hline No. of workers, No. & 3 & 12 \\
\hline Electricity quantity, $\mathrm{kWh}$ & 3.72 & 5.86 \\
\hline Weight of unit machinery, $\mathrm{kg}$ & 210 & 470 \\
\hline Fruit quantity, kg/h. & 300 & 300 \\
\hline Olive oil quantity, $\mathrm{kg} / \mathrm{h}$. & 45 & 45 \\
\hline
\end{tabular}

\section{Evaluation of Manual Energy Input (EM):}

Manual consumption energy was estimated by the following equations, for male worker the manual energy input was evaluated as the follows according to equation of Norman (1978): 
$\mathrm{EMm}=0.75 \mathrm{Ta}, \mathrm{MJ}$

Where, $\mathrm{EMm}=$ Male manual energy input, $\mathrm{MJ}$.

$0.75=$ Energy input of an average adult male, MJh- 1 .

$\mathrm{Ta}=$ useful time spent by a male worker per unit operation, $\mathrm{h}$.

For a female worker the manual energy input was evaluated as of

Norman (1978);

$\mathrm{EMF}=0.68 \mathrm{Ta}, \mathrm{MJ}$

Where, $\mathrm{EMF}=$ Female manual energy input, $\mathrm{MJ}$.

$0.68=$ Energy input of an average adult female, MJh-1

$\mathrm{Ta}=$ useful time spent by a female worker per unit operation, $\mathrm{h}$.

\section{Electrical Energy (EE):}

Electricity consumption $(\mathrm{kWh})$ was estimated from the following equation as reported by Pimentel (1992).

$\mathrm{EE}=11.99 * \mathrm{kWh}, \mathrm{MJ}$ 3

\section{Manufacture, Transport and Repair (MTR) Energy:}

Indirect mechanical energy was to be estimated by considering the energy expended to MTR from a unit mass of the machine obtained. The MTR energy was determined by (Bridges and Smith, 1979) as follows:

EMTR $=$ MTR x m, MJ................................. 4

Where: $\quad \mathrm{EMTR}=$ Indirect mechanical energy.

MTR = energy used to manufacture, transport and repair a unit mass of machinery, $100.7 \mathrm{MJkg}-1$.

$\mathrm{m}=$ Mass of machinery, $\mathrm{kg}$.

Hence for each of unit operation, the total energy input was:

$\mathrm{ET}=\mathrm{EM}+\mathrm{EFL}+\mathrm{EE}+\mathrm{EMTR}$ .5

Total Energy Content (Energy Output) of Finished Product:

This was evaluated from the equation below:

$\mathrm{EFP}=\mathrm{MFP} \times \mathrm{ECP}$

Where:

$\mathrm{EFP}=$ Total energy content of finished product, MJ.

MFP = Mass of finished product, $\mathrm{kg}$.

$\mathrm{ECP}=$ Energy content of a unit mass of product, MJkg-1

Energy Use Ratio: 
Energy use ratio was evaluated from the equation below:

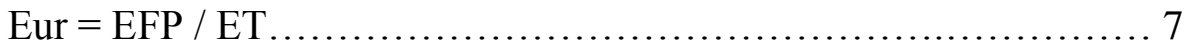

Where, Eur = Energy use ratio.

$\mathrm{EFP}=$ Total energy content of finished product, $\mathrm{MJ}$.

$\mathrm{ET}=$ Total energy input for operation, MJ.

\section{RESULTS AND DISCUSSION}

The results obtained from the present study show that the major energy sources that are used in the two extraction oil methods industries are manual, electrical and MRT energy. Hence, the results presented in the following sections.

Table 1: shows some of physical and mechanical properties of olive fruits. It noticed that the values were from 2.02 to $2.55 \mathrm{~cm}$, from 1.58 to $1.944 \mathrm{~cm}$, from 2.88 to $5.23 \mathrm{~g}$, from 50 to $49.85 \%$, and from 530 to 502 $\mathrm{N}$. for length, width, weight, moisture content, and hardness, respectively Energy input source in different extraction oil methods:

For the traditional energy input, the energy sources used were manual and electric and MRT. Tables 2 and 3 show the energy values from these sources while table 4 shows the total energy output of finished oil and energy use ratio.

Table 3: some of physical and mechanical properties of olive fruits.

\begin{tabular}{|c|c|c|c|c|c|}
\hline Item & Length, cm & Width, cm & Weight, g & $\begin{array}{l}\text { Moisture } \\
\text { content. , \% }\end{array}$ & Hardness, N \\
\hline Min & 2.02 & 1.58 & 2.88 & 50.00 & 530 \\
\hline Max & 2.25 & 1.94 & 5.23 & 49.88 & 502 \\
\hline Mean & 2.75 & 1.72 & 3.75 & 49.49 & 520 \\
\hline
\end{tabular}

Manual energy expended in operating machines was found to be the least consumed energy with values were 13.5 and $6.75 \mathrm{MJ}$ for manual and machinery methods, accounting for only $(0.06$ and $0.02 \%)$ of the total energy inputs. This could be due to the low number of industry workers deployed to perform individual operations.

\section{Comparison of input energy in both of traditional and machinery methods:}

For the MRT energy input, MRT energy consumptions, mostly expended in operating of manufacture, transport, and repairs were 2114.7 
and $47329 \mathrm{MJ}$ for traditional and machinery methods., which account for $99.9 \%$ of the total energy inputs. This due to the high number of industry MRT deployed to perform of traditional and machinery methods with its source of energy. (99.3 and 99.5\%) of the total energy inputs.

For the Electricity energy input, the various unit operations involved in olive oil production in olive oil company at the agricultural research center. Electrical energy expended in operating most of the machines/equipment accounted were 132.8 and 209.2 MJ for traditional and machinery methods. ( 0.6 and $0.4 \%$ of the total energy inputs).

Table 4 shows that in machinery input as energy input were highest, with value of $47544.9 \mathrm{MJ}$. This justifies the higher quantity of oil produced $(1000 \mathrm{~kg})$. The lowest energy consumption was recorded in traditional method with value of 21293.3 MJ. It was observed that in the production under machinery methods, energy use increased while oil production with manual methods was increased to $1000 \mathrm{~kg}$. The energy use ratios indicate that energy use was insufficient within the manual and machinery methods since in all cases, energy outputs were less than inputs.

Figs 2 and 3 show that from the identified energy use sources in the two traditional and machinery methods industries, it was observed that manual energy was usually expended in operating machines.This energy was the least used, accounting for less than $1 \%$ of the total energy consumed. This could be because of two reasons; firstly, due to low number of workers deployed to perform individual operations, and secondly due to inconsistent number of hours of work in a day. MRT energy expended in operating in the various industries has had the highest values of energy traditional and machinery methods use accounting for more than $90 \%$ of the total energy used. Electrical energy, which was expended for operating machines/electric motors varied from $5-10 \%$ of the total energy use depending on the sources as well as the industry.

Figure 2 shows the contribution of each energy source from the different sources for the two traditional and machinery methods. It is clear from the figure that much MRT energy was used by the industries in the traditional and machinery methods. It was also observed that MRT 
energy has relatively higher unit energy than the other sources of manual energy (electrical and manual). This implies that lower energy of production would have been expected if electricity supply had been steady. It is worth noting that the energy of MRT had an upward increase for 5-6 times during the period. After comparing the data of the two methods. Figure 3 shows the effect of total energy input and that of output against oil of production for the two agro allied industries, having total energy inputs greater than the total energy outputs.

Table 4: Manual, MRT and EE Energy Consumption at the olive oil company at Agricultural Research Center.

\begin{tabular}{|l|l|l|c|}
\hline $\begin{array}{l}\text { Extraction } \\
\text { methods }\end{array}$ & Requirements & Value, MJ & $\begin{array}{c}\text { Ratio of } \\
\text { total energy } \\
\text { input }\end{array}$ \\
\hline EMm, MJ & EMm $=0.75 *$ No. of Male & EMm, MJ & \\
\hline Traditional & $=0.75 * 6 * 3$ & 13.5 & 0.06 \\
\hline Mechanical & $=0.75 * 3 * 3$ & 6.75 & 0.02 \\
\hline MRT, MJ & MRT $=100.7 *$ kg of machine & MRT, MJ & - \\
\hline Traditional & $=100.7 * 210$ & 21147 & 99.3 \\
\hline Mechanical & $=100.7 * 470$ & 47329 & 99.5 \\
\hline EE, MJ & EE $=11.99 * \mathrm{kWh}$ & EE, MJ & \\
\hline Traditional & $=11.99 * 3.72 * 3$ & 132.8 & 0.62 \\
\hline Mechanical & $=11.99 * 5.86 * 3$ & 209.2 & 0.44 \\
\hline E total input, MJ & EM+EMRT + EE & E Total, MJ & \\
\hline Traditional & $13.5+21147+132.8$ & 21293.3 & \\
\hline Mechanical & $6.75+47329+209.2$ & 47544.9 & \\
\hline $\begin{array}{l}\text { E Total output, } \\
\text { MJ }\end{array}$ & $\begin{array}{l}\text { TEF Olive oil }=50 * \text { Oil }, \mathrm{kg} \\
(\text { liter })\end{array}$ & $\begin{array}{l}\text { TEF Total } \\
\text { output, MJ }\end{array}$ & \\
\hline Traditional & $=0.5 * 150$ & 75 & \\
\hline Mechanical & $=0.5 * 150$ & 75 & \\
\hline & Ratio $=($ output / input $) * 100$ & & \\
\hline Traditional & $75 / 21293.3 * 100$ & 0.352 & \\
\hline Mechanical & $75 / 47544.9 * 100$ & 0.158 & \\
\hline
\end{tabular}




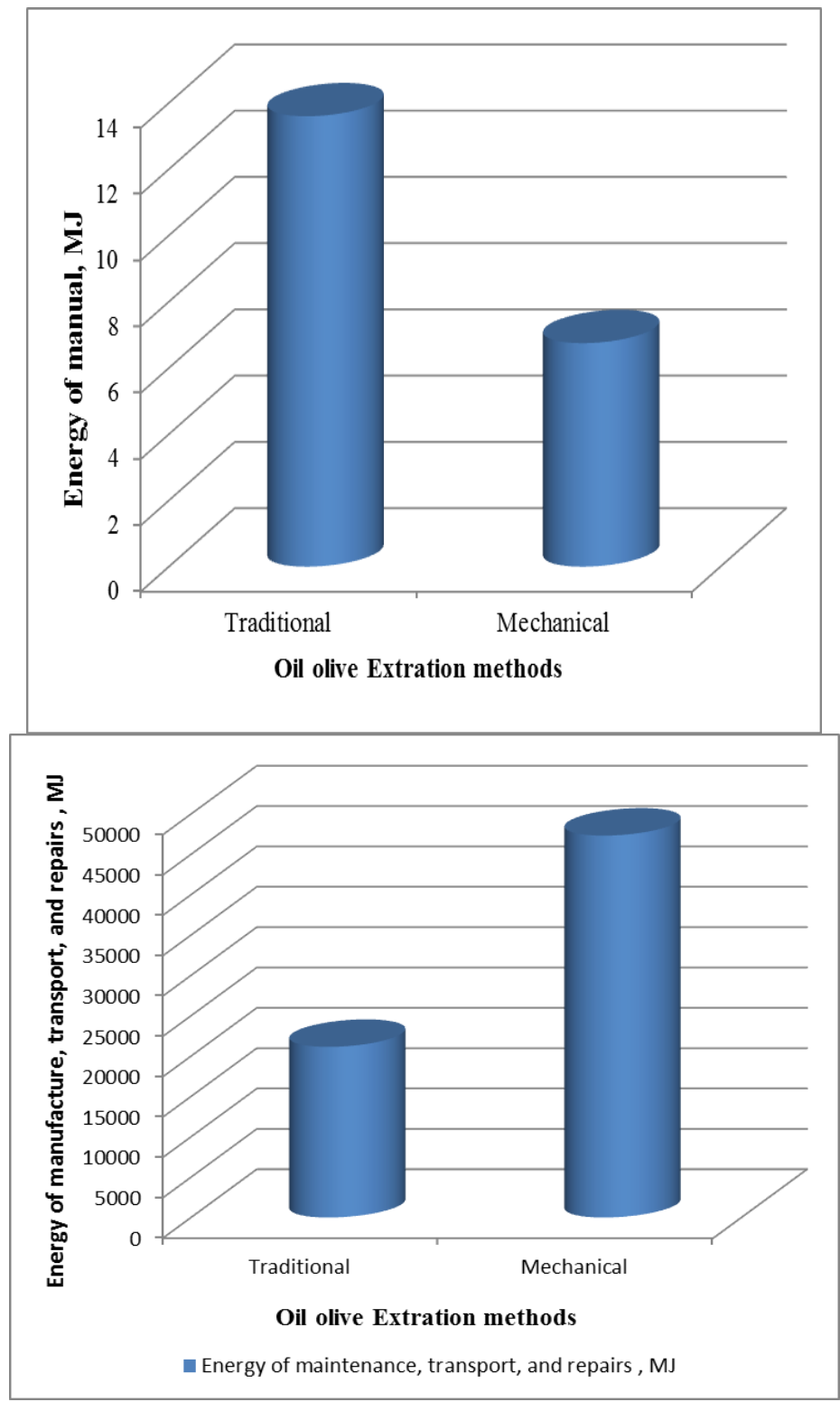

Fig. 2 : Energy of manual, and total of manufacture transport and repairs of traditional and mechanical methods 


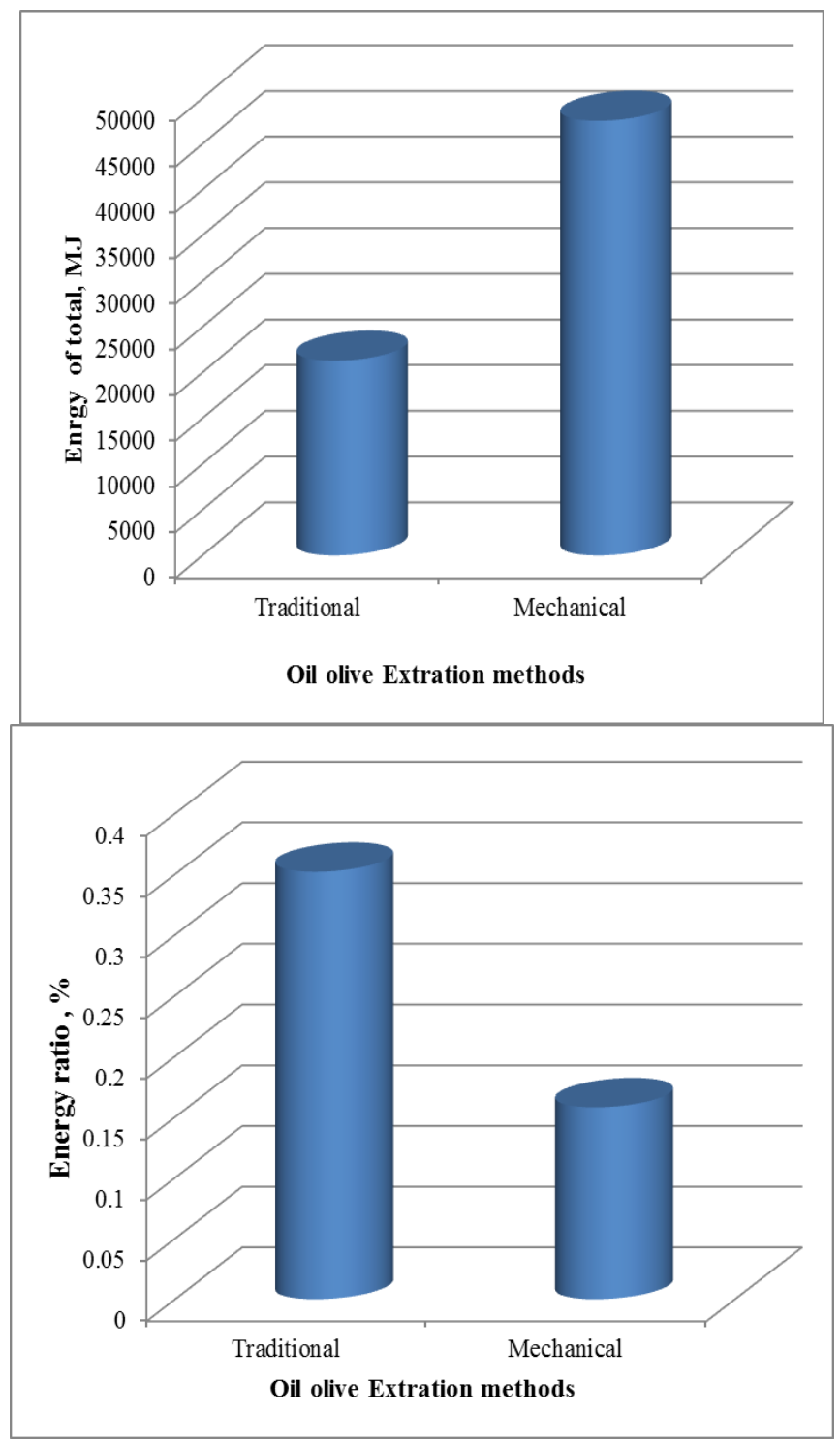

Fig. 3 : Energy and ratio of total input and output of traditional and mechanical methods

\section{CONCLUSIONS}

The study on patterns of energy use in traditional and machinery methods to oil extraction in olive oil Company in Agricultural Research Center revealed the following:

- Physical and mechanical properties of olive fruits. It noticed that the values were from 2.02 to $2.55 \mathrm{~cm}$, from 1.58 to $1.944 \mathrm{~cm}$, from 2.88 to 
$5.23 \mathrm{~g}$, from 50 to $49.85 \%$, and from 530 to $502 \mathrm{~N}$ for length, width, weight, moisture content, and hardiness.

- The major energy sources were manual, MRT and electrical energies. MRT energy was the highest energy consumed. MRT energy consumptions, mostly expended in operating of maintenance, transport, and repairs were 2114.7 and $47329 \mathrm{MJ}$ for traditional and machinery methods. In order to evaluate Manufacture, Transport and Repair (MTR) energy, equipment manuals should be kept intact for the purpose of indirect energy consumption analysis.

- Manual and electrical energy were expended in operating machines was found to be the least consumed energy with values were (13.5 and $6.75 \mathrm{MJ})$ and (132.8 and 209.2 MJ) for manual and machinery methods.

\section{LITERATURE CITED}

Abubakar M. and B.Umar (2006). "Comparison of Energy Use Patterns in Maiduguri and Yobe Flour Mills, Nigeria"Department of Agricultural Engineering, Bayero University. Agricultural Engineering International: the CIGR E. journal. Manuscript. EE 06 004. Vol. VIII. Pages : 1-6.

Akinbami, J. F.; M. O. Ilori; A. A. Adeniyi, and S. A. Sanni (2001). Improving Efficiency of Energy Use in Nigeria's Industrial Sector: A Case Study of a Beverage Plant. Nigerian Journal of Engineering Management 2(2):1-8.

Al Kurki, Janet Bachmann and Holly Hill, (2008). Plant Benefits: Olive oil lines for batch and continuous processing, Oilseed Processing for Small-Scale Producers:

Alam, M.S. (2007). Basic of fats and Oils Chemistry: Factors Affecting Crude Oil Quality. Presented to the Vegetable Oils Extraction Short Course, Texas A\&M Food Protein R\&D Center, College Station, Texas. Page 28

Alcaide, E. M. and A. Nefzaoui (1996). Recycling of Olive Oil byProducts: Possibilities of utilization in Animal nutrition, International Biodeteriotation \& Biodegradation, p. 227-235, Elsevier Science Limited, UK

Boskou, D., G. Blekas and M. Tsimidou (2005). Phenolic compounds in olive oil and olives. Current Topics in Nutraceutical Res., $3(2), 125-136$. 
Bridges, T. C. and E. M. Smith (1979). A method of determining the total energy input for agricultural practices. Transactions of the ASAE, 2:781 - 784 .

Chinnan, M. S.; R. P.Singh; L. D. Pederson; P. A. Carroad; W. W. Rose and N. L. Jacob (1980). Analysis of Energy Utilization in Spinach Processing. Transactions of the ASAE 23:503-507.

Fellows, Peter, and Ann Hampton (1992). Small- Scale Food Processing: A Guide to Appropriate Equipment. Practical Action Publishing - formerly the Intermediate Technology Development Group. 158 p.

Gutierrez, F.; T. Arnaud and A. M. Albi (1999). Influence of ecological cultivation on virgin olive oil quality. J. Am. Oil Chem. Soc. 76 (5): 617-621.

Herz, J. (1997). Using and Maintaining the Ram Press. Enterprise Works Worldwide. Washington, DC. 42 p.

Igene, J. O.; M. M. Farouk and C. T. Akanbi (1990). Preliminary Studies on the Traditional Processing of Kilishi. J. SCI. Food Agric. 50: 89 - 98 .

Jekayinfa, S.O. and E.O. Olafimihan, (2000). A Study and Analysis of Energy Consumption in Beverage Producing Plants in Nigeria. The Annual Conference of Nigeria Institute of Industrial Engineers, Ibadan. 12th-17th, October.

Kurki M., I. Beheshti Tabar, and G.M. Khubbakht (2008). Energy Production in Iran's Agronomy. Department of Agricultural Machinery Engineering, Faculty of Biosystems Engineering, University of Tehran, Iran Am-Euras. J. Agric. \& Environ. Sci., 4 (2): 172-177.

Ministry of Agriculture and Land Reclamation of Egypt (2014). The production of high-quality olive oil according to, technical bulletin No. 2/2014 / issued.

Norman, M. J. T. (1978). Energy Inputs and Outputs of Subsistence Cropping Systems in the Tropics, Agro-Ecosystems, 4:355 - 366.

Owen, R. W., A. Giacosa, W. E. Hull, R. Haubner, G. Wurtele, B. Spiegelhalder and H. Bartsch (2000). Olive oil consumption and health: The possible role of antioxidants. Lancet Oncology, 1: 107112 . 
Pilgeram, A. (2008). Principles of Oil Extraction. Practical Action Publishing, Small Scale Grain and Pulse Production forum. Colchester, Essex, UK.

Pimentel, D. (1992). Energy Inputs in Production Agriculture. Energy in Farm Production, Elsevier, and Amsterdam. Pp.13-29.

Van Gerpen (2006). Building a Successful Biodiesel Business. Second edition. Biodiesel Basics. 277 p

Van Gerpen, J. (2008). Small Scale Grain and Pulse Production forum. May 17, 2008. Cleaning Up. Small Scale Grain and Pulse Production: A Forum for Information on Grain and Pulse Production for Food.

\section{الملخص العربيى \\ الطاقة المستهلكة فى عملية استخلاص زيت ثمار الزيتون بطرق مختلفة

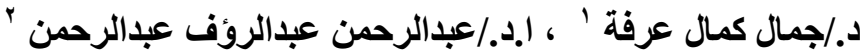

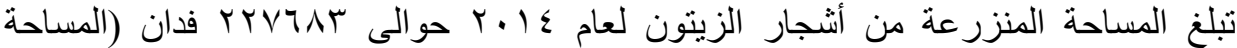

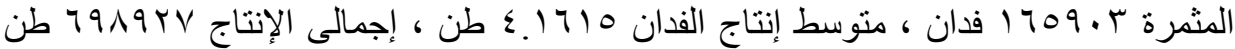

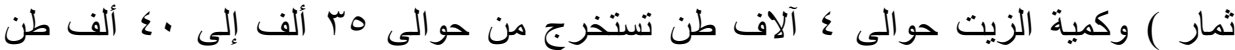

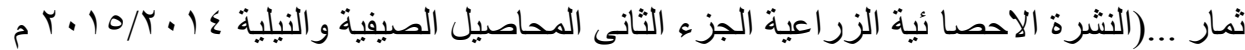

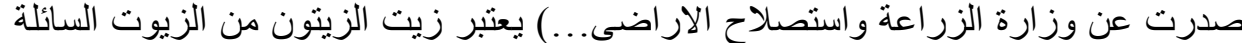

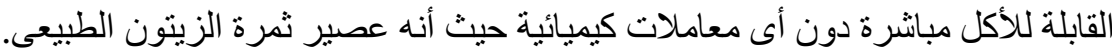

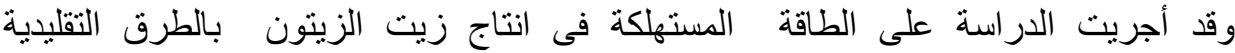

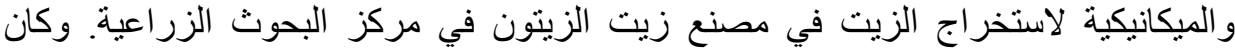

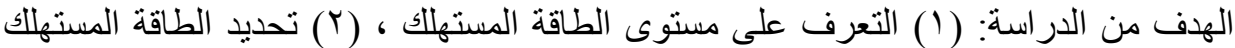

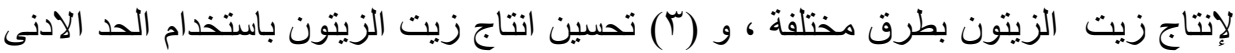

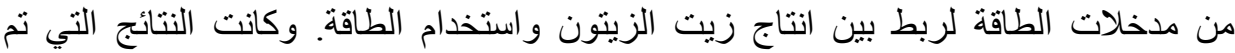

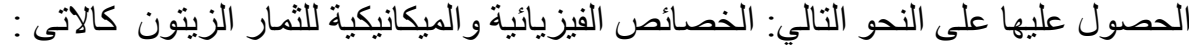

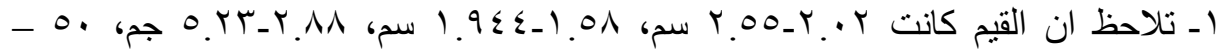

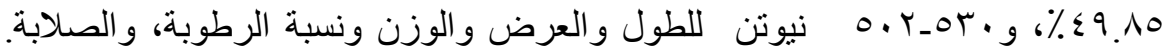
r ـ كانت مصنادر الطنيب.

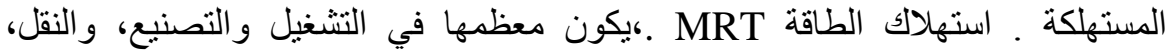

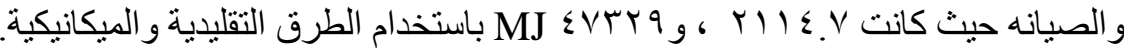

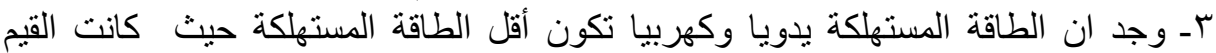

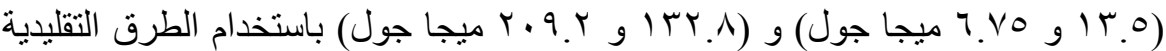

و الميكانيكية.

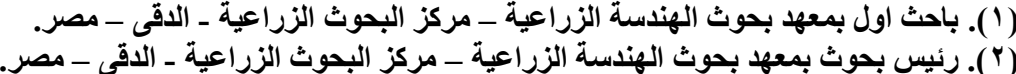

